\title{
A Framework for Delivering Personalized e-Government Services from a Citizen-Centric Approach
}

Malak Al-Hassan
Haiyan Lu

Jie Lu

\author{
Decision Systems \& e-Service Intelligence Lab \\ Quantum Computation \& Intelligent Systems Centre \\ Faculty of Engineering \& Information Technology \\ University of Technology, Sydney \\ P.O. Box 123 Broadway, NSW, Australia 2007 \\ \{malak, helenlu,jielu\}@it.uts.edu.au jielu@it.uts.edu.au
}

\begin{abstract}
E-government is becoming more attentive towards providing intelligent personalized online services to citizens so that citizens can receive better services with less time and effort. This paper proposes a new conceptual framework for delivering personalized e-government services to citizens from a citizen-centric approach, called Pe-Gov service framework. This framework outlines the main components and their interconnections. Detailed explanations about these components are given and the special features of this framework are highlighted. The Pe-Gov framework has the potential to outperform the existing e-Gov service systems as illustrated by two real life examples
\end{abstract}

\section{Categories and Subject Descriptors}

H.1.2. [Information Systems]: Models and Principles user/machine systems, human information processing

\section{General Terms}

Design

\section{Keywords}

Citizen-centric, e-government services, personalization, user profile, framework

\section{INTRODUCTION}

E-government (e-Gov) refers to the use of innovative systems, information and communication technologies (ICTs) to achieve better services to citizens and businesses [1]. The benefits of using e-Gov include reduction of costs, revenue growth, transparency and accountability to governments, greater convenience, increased productivity and a good control of fraud and corruption [2]. EGov services have a great potential for delivering better governmental services to citizens, improving the quality of the provided services, improving the access to information/service (24 hours a day, 7 days a week). The full potential benefits of e-Gov services will not be fulfilled if the usage of e-Gov services is low [1]. In order to increase the usage of e-Gov services and make eGov services more attractive to citizens, the development of eGov services should adopt intelligent techniques [3] and deliver services in a citizen-centric approach, from which e-Gov could improve the delivery of its services to citizens on a personalized basis to ensure that the heterogeneous citizen's needs and interests are met without excessive input from the users [4, 5]. The projected future development stage in e-Gov is to provide intelligent personalized online services to citizens and businesses, which would make e-Gov attract more and more citizen and businesses to use/access the provided e-services [3, 6].
Personalized online service is considered as a process of getting web users' information online and using these information to tailor services to users' needs and preferences [7, 8]. It consists of three basic phases: collection of web data, processing of collected data and delivery of personalized output.

Personalization is relatively new to the public sector although it has been widely used in e-commerce applications. Personalization aims to provide users with what they want without asking them explicitly about their needs [9]. The research on personalization in e-Gov context is in the stage of concept formation and conceptual model building. Further research on implementing personalization in e-Gov is desirable. However, due to the expected obstacles when implementing a single national wide personalized e-Gov portal, such as governance regulations, process redesign, and privacy issues, it has been suggested that a domain specific personalized e-Gov service is a good starting point to implement personalization in public sector [10].

A few leading countries in e-Gov service developments, such as Singapore and Canada, have offered their citizens simple personalization services through their official portal websites [11]. However, these personalized services are static customization and very limited and far from achieving citizen-centric e-Gov services. More advanced and intelligent e-Gov systems are highly desirable.

Recommendation system (RS) is one of the most popular applications of personalization and has been widely used in web personalization and e-commerce applications. The aim of RS is to provide customers with personalized services or products that relevant to their needs and interests. This can be achieved by filtering out the unrelated services automatically and suggesting only the relevant ones to the users [9].

Government services are highly regulated and deal with heterogeneous information. They are more prone to change because government regulations often subject to change. Additionally, a particular government agency may require access to a variety of data sources in order to tailor its service to a particular citizen $[12,13]$. These aspects of government services make the personalization more difficult. Therefore, it is highly desirable to semantically represent various aspects of e-Gov services and their characteristics [14]. Ontology describes precisely the meaning of knowledge. It represents explicit formal specifications of the entities in the domain and relations among them and could ultimately provide a concise communication in high complexity environments $[15,16]$. Utilizing an ontology creates a semantic access to information in high complex environments and provides effective means for representing and 
describing information in high level of abstractions [13, 17]. Ontologies have been used as knowledge management approach to e-Gov services [18], as management system to keep the consistency of e-Gov services which subject to change [19], as solution to facilitate the access to the administrative information in the e-Gov services for a specific domain [20], and as means to achieve integrated public service delivery [21]. It is promising to use ontology for better presentation of information within the domain e-Gov and implicitly inferring users' needs for better personalization.

This paper focuses on e-Gov services offered by Government to Citizens (G2C). It proposes a new conceptual framework of a domain-specific personalized e-Gov services with recommender systems from a citizen-centric approach. This framework outlines the main components and their interconnections. It has the potential to outperform the existing e-Gov service systems.

The rest of the paper is organized as follows: Section 2 presents the proposed framework. Section 3 illustrates the work flow of the proposed framework with the comparison to the current e-Gov service systems through two real life cases. Section 4 concludes the paper and points out the further work.

\section{A CONCEPTUAL FRAMEWORK OF PERSONALIZED DOMAIN SPECIFIC E-GOV SERVICES}

Aiming at delivering the most relevant domain specific e-Gov services to citizen with least user input, we propose a conceptual framework of personalized domain specific e-Gov services from citizen centric approach, called Pe-Gov, as depicted in Figure 1. This framework is comprised of four main components: the User Interface component, the User Data Collector component, the Intelligent Recommendation Engine component, and the Data Source Repository component. These components are jointly work together to offer the most relevant recommendations that meet the citizens' requirements. It can be applied to various government departments, such as education, tourism, welfare, and healthcare departments.

Under this framework, a Pe-Gov service system will offer the most relevant recommendations to each individual citizen using advanced intelligent techniques in two fashions: auto and ondemand recommendations. The on-demand personalized recommendations are offered upon a service request from a user while the auto personalized recommendations are offered to users according to their profiles without their specific requests.

One of the highlights of this framework is the citizen-centric approach, from which the proposed framework focuses on offering personalized recommendations to citizens with least input from them. It builds users' confidence by asking as least as possible personal information and allows them to view and modify their personal information. It meets users' needs by offering the most relevant e-Gov services through applying advanced RS techniques and ontology based semantic reasoning. It also strives to satisfy users by seeking users' feedbacks on the provided e-Gov services. Such feedbacks could help government (i) understand citizens' expectations; (ii) assess if the provided personalized services meet citizens' needs and if they are delivered in an efficient and friendly manner; (iii) enable further improvement to the delivery of e-Gov services. Users' confidence, needs, interests, and satisfaction are the key points that the proposed framework is built upon.

The following subsections will give general description of each main component with focus on conceptual functionality of each component rather than technical details, which could only be determined by a specific application domain.

\subsection{User Interface}

This User Interface (UI) component facilitates the interaction between users and the system, such as user registration, user login, user on-demand request and corresponding recommendations, and user feedbacks. It consists of two units: Registration or login unit and the customized user interface (CUI) unit. The CUI unit is the actual interactive interface between the system and an active user. It will be generated based on the user's information, including user's demographic information, personal interests and needs within the given domain of e-Gov services, which can be obtained from the registration unit and data collector component.

Through the UI component, a user can perform the following actions:

U1. Subscribe to the system using a registration form, in which a user needs to provide his/her demographic data and personal interests and preferences of services in the specific domain;

U2. Login to the system every time he/she want to use the system;

U3. Navigate the hierarchical service catalogue which is based on the domain specific ontology;

U4. Specify a request for a particular service by clicking the service item in the service catalog;

U5. View the most relevant recommendations on a specific service;

U6. View and update his/her demographic information or interests and preferences; and

U7. Provide feedback on the recommendations received or the actual experience in using the services.

Enabling users to view and modify their personal information can enhance the trust between the users and the e-Gov service providers and this will reduce the users' tension about giving out their personal information.

Through the UI component, the system can perform the following actions:

S1. Facilitate the registration or logon process;

S2. Conduct questionnaire-based survey when necessary;

S3. Present the hierarchical structure of the domain-specific eGov services based on the domain specific ontology;

S4. Present interactive dialogs to collect user's specified request;

S5. Present the personalized output as recommendations for a given user's request or an automatic recommendations for the user's interests and preferences; and

S6. Present the users' feedback forms for collection the users' feedback on the personalized recommendations and the e-Gov services.

\subsection{User Data Collector}

The User Data Collector (UDC) component is responsible for collecting the users' information, including the demographic information, personal interests and preferences to the domain 
specific e-Gov services and the user's e-Gov service usage history. This component will perform two tasks:

- Collect User's Data: This task is to capture the user's data from the system, which includes actions (S1-S3 and S7) in the UI component. Based on the literature, implicit and explicit acquisitions can be used for collecting user related data for web personalization $[22,23]$. An implicit acquisition will be used to trace a user's navigation sequences from U3 to collect data about citizens' preferences or interests implicitly. The explicit acquisitions will be used with the actions S1-S3 and action S7 to capture user related data, including the users' demographic data as well as the data about their skills, experiences, interests and preferences through pre-defined forms, such as the registration and questionnaire forms, or preference dialogs.

- Update User's Profile: This task is to regularly update the user profile DB by recording the captured data from the above unit into the DSR component.

\subsection{Data Source Repository}

The Data Source Repository (DSR) component is responsible of storing all the data that is required for generating required personalized e-Gov services. It comprises of domain ontology of a specific e-Gov services and a user profile database.

\subsubsection{Domain Specific e-Gov Ontology}

Domain specific e-Gov ontology will define the main concepts that used to represent the available services offered to the public, the relationships linking the concepts and the associated inference rules. These concepts could include the offered services, the government's rules that regulate the operation of the services, and forms etc. A concept can have descent concepts. Each concept has specific properties, e.g. the service name, service description and service consumer type. The relationships link the concepts, e.g. the relationship "regulate" links the concepts "service" and "rules" concept, and the relationship "hasforms" links the concepts "service" and "forms". Specific ontology for an e-Gov domain will expose how the available services are interacting with each other semantically at different level of hierarchy.

The ontology schema has three main roles in the framework: i) guide the hierarchical representation of available e-Gov services in the CUI unit (S3); act as a means of tracing the users' navigation sequences which can be used to extract the users' interests and preferences implicitly in UDC component; and iii) be used in the IRE component to facilitate the semantic rule reasoning to find the matching between the available services and users' requests, which could enhance the retrieval of the appropriate content for each user.

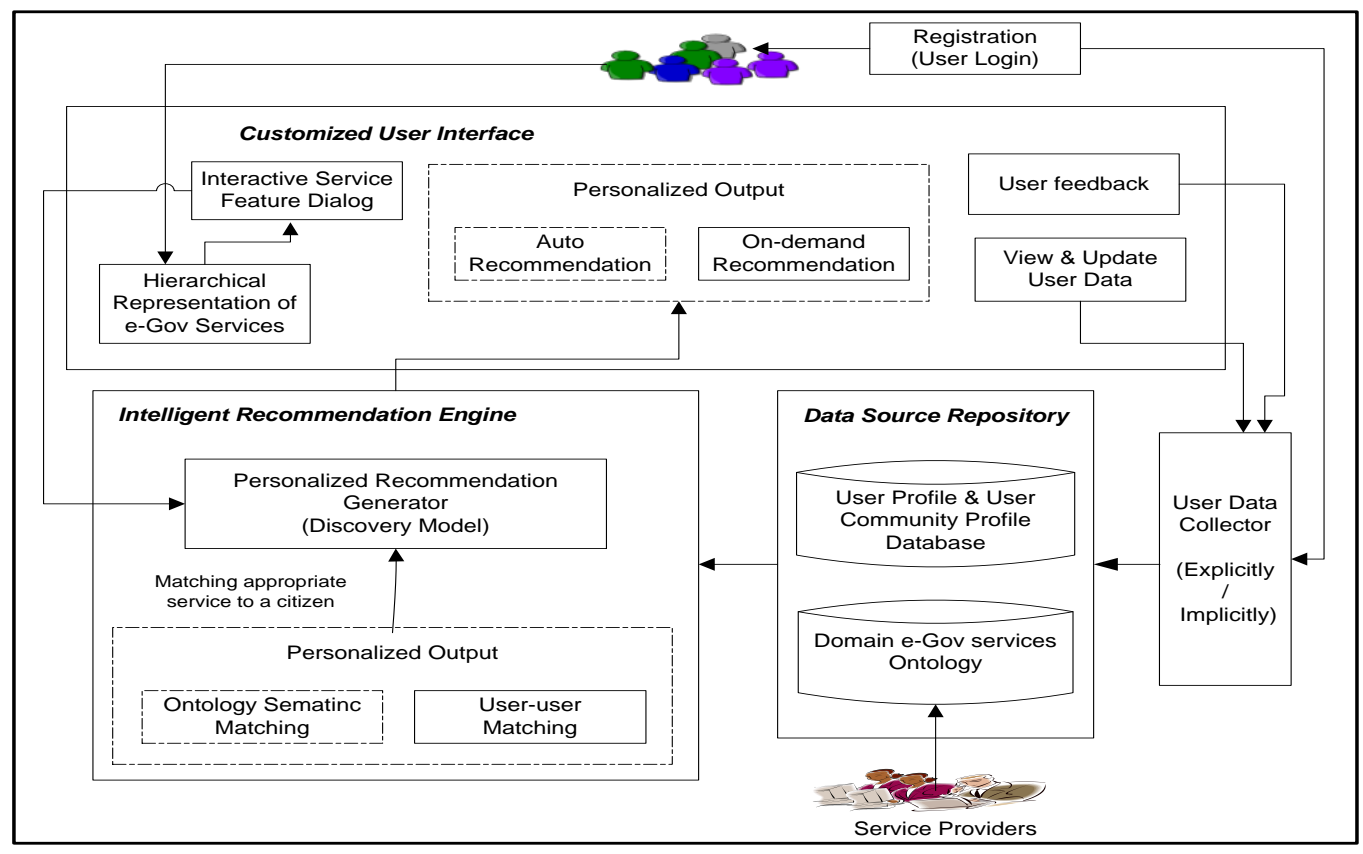

Figure 1: Framework of a domain-specific Pe-Gov Service System

\subsubsection{User Profile $D B$}

| User profiling would help e-Gov service systems to communicate effectively and efficiently with their users. With the provision of user profiles, the systems can recognize the user every time he/she logon to the system and the user does not need to enter the same personal information again. This will make users' interactions with the system easier and faster. A user profile can be defined as a structured data record storing user-related data, which can be either static or dynamic. Static data contains the user information that never or rarely changed, such as demographic information (e.g. ID, name, gender, birth date, address, salary, etc); whereas the dynamic data contains the user information that is frequently updated (e.g. interests/preferences, skills, expertise, etc). User profiles form an information base which provides the most relevant information of the identification and behavior of the user $[23,24]$. It also enables the IRE component to find the most suitable services for a given user and to predict a user's future behavior towards using the services without excessive input from the users in the IRE component. 
A user community is introduced to represent a group of users who share common characteristics, and interests and/or needs in a specific e-Gov domain. User communities can be formed based on the user profiles using the clustering techniques in data mining. Due to heterogonous nature of users' interests and needs in e-Gov services, a user can be in one or more user communities. Each user community has distinguished features which can be used for generating recommendations to the members in this community. User community members will be dynamically updated according to the changes of constituent members' profiles.

\subsection{Intelligent Recommendation Engine}

The Intelligent Recommendation Engine (IRE) component is responsible for generating the recommendations of the most relevant services to the given users based on their interests and/or requirements. It is composed of two units, the data matching analyser (DMA) and the personalized recommendation generator (PRG).

\subsubsection{Data Matching Analyzer (DMA)}

The Data Matching Analyzer (DMA) unit aims to find the matching (or correlation) degrees between the user's request and the available e-Gov services. The matching degree can be calculated using two similarity measures. One is the service-toservice similarity that describes the matching degree between the requested service(s) by a user and the available e-Gov services. This similarity can be computed based on the semantic ontology matching, which can be inferred by semantic analysis based on the inference rules for all the service instances in the ontology. This similarity will be computed periodically offline and stored in DSR component.

The other one is the user-to-user similarity which describes the matching degree between the profile of a given user and profiles of other users who belong to the community profile of that user. Machine learning approaches, data mining techniques, and recommendation system techniques can be used for the computation of the user-to-user similarity.

\subsubsection{Personalized Recommendation Generator}

This unit uses the matching degree, i.e., the service-to-service similarity and the user-to-user similarity, to build different classification and regression-based discovery models. These models are used to predict the most relevant services among the available services for a given user. Based on the outcomes of applying these models, PRG will generate relevant services for each citizen as personalized output in two types of recommendation; on-demand and Auto personalized recommendations. For the on-demand personalized recommendation, a user needs to navigate the hierarchical representation of the e-Gov services and select the required service. The system will ask more information about the required service from the user through an interactive service feature dialogue. The completion of the feature dialogue will trigger the PRG unit to start generating the recommendations using the user's request, specifications of the requested service, user profile and the matching degree obtained from DMA unit. The recommendation output will be presented as a list of top- $N$ most relevant services that match the citizen's request. For the auto personalized recommendation, the recommendation generation will be triggered automatically by an event, which can be a new service added to the system, or new changes of government rules, or the updates of user profiles, and the recommendations are generated offline and presented as notification to users in the user's customized user page.

\section{IMPROVEMENTS OVER THE CURRENT E-GOV SERVICE SYSTEMS}

Two current e-Gov systems are selected for the comparisons between the proposed e-Gov framework and the current e-Gov systems: One is the web site hosted by the Australian Department of Education, Employment and Workplace Relations (DEEWR), (http://www.deewr.gov.au). This web system offers citizens numerous educational and employment related services. The other is the Australian welfare online service hosted by Centrelink (http://www.centrelink.gov.au/) which is an Australian Government Statutory Agency to offer various welfare related services to Australians. Some of the services in these two websites are offered on an individual basis, such as the online payment and job seeking. However, these services are limited to providing a secured online transaction or a communication channel between users and government agencies or potential employers. They are not personalized recommendations offered in the services. The following two cases show the significance of the proposed framework compared to the current e-Gov service systems.

Case 1: A girl is about to finish her high school study and would like to go on for tertiary study in a university. She wants to find out what scholarships are available for her. How the current DEEWR online service and the proposed framework can help?

Using the current DEEWR website, she needs to type in the key word "scholarship" and run a key-word search. The system will return her all the information related to "scholarship", which are about 400 different links to scholarships, including the scholarships for local school leavers, for international undergraduate/postgraduate students. In order to find out which is the best for her, she has to visit most of the links if not all to find out the scholarship(s) that can meet her requirements. This will waste her a lot of time and efforts in filtering out the irrelevant information and very likely gives her unpleasant searching experiences.

Using the proposed framework, she needs to register with the system. During the registration, the system captured her personal information, such as occupation, date of birth, education background, nationality, career and prospective career direction. After login to the system, she can browse the service catalogue, which is a hierarchical representation of all available services, for the node of "scholarship". When she clicks the node, an interactive dialogue window will pop-up to ask for some specific information about the scholarship she is looking for, such as "for local student", "for school leaver", "preferred university", "study area" and "estimated academic achievement level". The IRE component will consolidates the information from her user profile, her user community profile and the specific information from the dialogue, and then generates a few most relevant scholarships for her as the on-demand recommendations (using the PRG unit that described in section 2.4.2). This will save her significant amount of time and efforts and bring her pleasant searching experience. Furthermore, her navigational pattern in the service category and the information given in the dialogue will be captured by the system and her interests and intentions behind this navigation will be inferred and stored in her user profile for future use. 
Case 2: A mother of two young children is a full time employee. The changes of taxation rules will effect her entitlement of family benefit. How the current Centrelink online service and the proposed framework can help?

Using the current Centrelink online service, she can only browse through all the news about the changes and figure out how the taxation rule changes will effect her entitlement.

Using the proposed framework, she needs to register with the system. During the registration, the system captured her personal information, such as single mother, number of children (two kids), occupation, full-time work, estimated annual income, and nationality/residential status. For any governmental rule changes, IRE will infer the effects of the changes on the entitlement of the affected groups and generate auto-recommendations for the members in the affected groups. For this particular case, the taxation rule changes will affect the entitlement of social benefits

for single mothers and this mother will be affected. A notification will be automatically presented in her customized web page. If any event that will change her profile, such as her income changes, and her children becoming independent, the IRE component will also be triggered to generate notifications to her.

\section{REFERENCES}

1. Accenture, eGovernment Leadership: high performance, maximum value. Fifth Annual Accenture eGovernment study. 2004.

2. Fang, Z., E-government in digital era: concept, practice, and development. International Journal of The Computer, The Internet and Management, 2002. 10(2): p. 1-22.

3. Guo, X. and J. Lu, Intelligent E-Government Services with Personalized Recommendation Techniques. International Journal of Intelligent Systems, 2007. 22(5): p. 401-417.

4. Kašubienè, L. and P. Vanagas, Assumptions of E-government Services Quality Evaluation. Engineering Economics 2007. 5(55): p. 68-74.

5. Undheim, T.A. and M. Blakemore, A Handbook for Citizencentric eGovernment, I.S. European Commission, Editor. 2007.

6. Layne, K. and J. Lee, Developing fully functional egovernment: a four stage model. Government Information Quarterly, 2001. 18(2): p. 122-36.

7. Lu, J., D. Ruan, and G. Zhang, eds. E-Service Intelligence: Methodologies, Technologies and Applications. 2007, Springer.

8. Schewe, K.-D. and B. Thalheim, Personalisation of web information systems $-A$ term rewriting approach. Data \& Knowledge Engineering, 2007. 62(1): p. 101-117.

9. Goy, A., L. Ardissono, and G. Petrone, Personalization in ECommerce Applications, in The Adaptive Web: Methods and Strategies of Web Personalization, P. Brusilovsky, A. Kobsa, and W. Nejdl, Editors. 2007, Springer, Heidelberg (2007) p. 485-520.

10. Pieterson, W., W. Ebbers, and J.v. Dijk, The Opportunities and Barriers of User Profiling in the Public Sector in Electronic Government 2005, Springer Berlin / Heidelberg. p. 269-280.

11. Accenture, Leadership in Customer Service: Delivering on the Promise. Available at: http://nstore.accenture.com/acn_com/PDF/2007LCSDelivPro miseFinal.pdf. 2007.

12. Lee, J. and H.R. Rao, Task complexity and different decision criteria for online service acceptance: A comparison of two egovernment compliance service domains. Decision Support Systems, 2009. 47(4): p. 424-435.

13. Medjahed, B., et al., Infrastructure for e-government web services. IEEE Internet Computing, 2003. 7(1): p. 58-65.
Meanwhile, her user community may be adjusted and new recommendations may be generated accordingly.

In summary, the proposed framework can offer users personalized e-Gov services based on their interests/preferences, characteristics and personal needs with least input from users. It can significantly improve the current e-Gov services.

\section{CONCLUSION AND FUTURE WORK}

A new conceptual framework of a domain specific personalized eGov services, Pe-Gov, has been proposed from the citizen-centric approach. The main components of the Pe-Gov were discussed. The proposed framework has several distinguished features including being citizen centric; building comprehensive user profiles; adopting personalization techniques; using domain ontology; and using user community concept in generating intelligent recommendations. Its potential of offering better personalized e-Gov services to users has been illustrated by two real life cases. The future work would be to develop the detailed framework of personalized e-Gov services in a particular domain and then develop a working system to deliver the personalized eGov services to Citizens.

14. Vassilakis, C. and G. Lepouras, An Ontology for e-Government Public Services. Encyclopedia of E-Commerce, E-Government and Mobile Commerce 2006.

15. Gruber, T.R., Toward Principles for the Design of Ontologies Used for Knowledge Sharing. nternational Journal HumanComputer Studies, 1995. 43(5-6): p. 907-928.

16. Li, M., X.Y. Du, and S. Wang. Learning ontology from relational database. in Proceedings of the Fourth International Conference on Machine Learning and Cybernetics. 2005. Guangzhou, China: IEEE.

17. Klischewski, R. and M. Jeenicke. Semantic Web Technologies for Information Management within e-Government Services. in Proceedings of the 37th Hawaii International Conference on System Sciences. 2004: IEEE.

18. Fraser, J., et al., Knowledge Management Applied to eGovernment Service: The Use of an Ontology, in Knowledge management in electronic government, M.A. Wimmer, Editor. 2003, Springer.

19. Stojanovic, L. and D. Apostolou, Ontology-based Change Management of e-government services, in Proc. of WI2005 Conference-" Semantics and Orchestration of eGovernment Processes. 2005: France.

20. Bettahar, F., C. Moulin, and J.-P.A. Barthe. Ontologies supporting eGovernment Services. in The 12th Portuguese Conference on Artificial Intelligence. 2005.

21. Overbeek, S., M. Janssen, and P.v. Bommel. An Ontological Framework for Integrated Public Service Delivery. in Proceedings of the Third International Workshop on Ontology, Conceptualization and Epistemology for Information Systems, Software Engineering and ServiceScience held in conjunction with CAiSE'09 Conference. 2009. Amsterdam, Netherlands: CEUR-WS.org.

22. Markellou, P., et al. Personalized E-commerce Recommendations. in Proceedings of the 2005 IEEE International Conference on e-Business Engineering (ICEBE'05). 2005: IEEE Computer Society.

23. Eirinaki, M. and M. Vazirgiannis, Web mining for web personalization. ACM Transactions on Internet Technology (TOIT), 2003. 3(1): p. 1-27.

24. Markellou, P., M. Rigou, and S. Sirmakessis, Web Personalization for E-marketing Intelligence, in Contemporary Research in E-marketing, S. Krishnamurthy, Editor. 2004, Idea Group Publishing. 